Chemotherapy-induced temporary hair loss is one of the most common and very distressing side effects of cancer therapy. Because of it, prevention of alopecia should be an important part of treatment. Various physical and pharmacological methods have been used with only moderate success until now. Although the scalp tourniquet method causes moderate hair preservation, this process is time-consuming, uncomfortable and may lead to ischaemic nerves damage. Low temperature and pulsed electric field are promising physical factors. Scalp hypothermia has become an increasingly effective, simple and inexpensive method. Hypothermia should not be used in patients with haematological malignancies since cooling prevents the effect of chemotherapy on tumour cells in the skin. Electrotrichogenesis, or the use of a specific pulsed electric field, has shown promising results in preventing chemotherapyinduced hair loss without attributable side effects.

Key words: hair, alopecia, side effect, chemotherapy, cytostatic drugs, hypothermia, electrotrichogenesis.

\section{Hair loss as a consequence of cancer chemotherapy - physical methods of prevention. A review of the literature}

\author{
Tomasz Dąbrowski
}

Department of Physics and Biophysics, Medical University of Gdansk

\section{Introduction}

The last 20 years have seen significant progress in preventing undesirable side effects of cancer chemotherapy. Nausea and vomiting, as well as haematological disorders, infections and pain can now be markedly reduced.

For a chemotherapy patient, alopecia is one of the three most severe effects of chemotherapy (second only to the lack of acceptance by the patient's family and friends, and immediately followed by fatigue) [1]. Hair loss is thus a very undesirable consequence of chemotherapy and further studies are needed to determine how it can be reduced. Physical and pharmacological methods applied in order to halt the process of hair loss have remained largely unchanged over the years, even though none of them seems sufficiently effective. The superficial nature of chemotherapy alopecia, and the fact of it being limited to the scalp, opens up treatment possibilities mainly for physical methods due to easy application.

Alopecia is caused by a number of cytostatic agents (Table 1). The occurrence and duration of hair loss, as well as its severity, depend on a variety of factors including type and dosage form of the cytostatic drug, dosage regimen, duration of chemotherapy cycle, route and duration of administration, elimination half-life of the drug (and its active metabolites), and monotherapy vs. combination chemotherapy. Combination chemotherapy involving multiple cytostatic agents triggering hair loss may exacerbate the effect (accumulated toxicity). Intravenous administration causes heavier hair loss than administration via the oral route. Taxoids used in low doses in a weekly cycle result in less severe alopecia than used in higher doses at three-week intervals. Liposomal doxorubicin, as opposed to the solution (the traditional dosage form of the drug), results in less pronounced hair loss [1].

\section{Effect of cytostatic agents on hair follicles}

Over their lifetime, hair follicles grow in repeated cycles encompassing three main phases:

- active growth phase (anagen) - new hair growth; between 24 and 72 months;

Table 1. Cytostatic drugs that cause alopecia and their severity [1]

\begin{tabular}{|c|c|c|}
\hline \multicolumn{3}{|c|}{ Severity of hair loss } \\
\hline mild & moderate & severe \\
\hline $\begin{array}{l}\text { bleomycin } \\
\text { carmustine } \\
\text { 5-fluorouracil } \\
\text { cisplatin }\end{array}$ & $\begin{array}{l}\text { methotrexate } \\
\text { mitomycin } \\
\text { actinomycin } \\
\text { teniposide } \\
\text { topotecan } \\
\text { irinotecan }\end{array}$ & $\begin{array}{c}\text { cyclophosphamide } \\
\text { daunorubicin } \\
\text { doxorubicin } \\
\text { paclitaxel } \\
\text { docetaxel } \\
\text { vinblastine } \\
\text { vincristine } \\
\text { vindesine } \\
\text { ifosfamide } \\
\text { etoposide }\end{array}$ \\
\hline
\end{tabular}


- end of active growth phase (catagen) - hair decay phase; ca. 3 weeks;

- resting phase (telogen); 3-4 months.

The duration of individual phases varies for different follicle types, sex and body area. Ca. 85-90\% (min. 60\%) of scalp hair follicles are in the anagen phase. A markedly smaller proportion (ca. 10-30\%) is hair in the telogen phase. Hair follicles in the catagen phase are the smallest group, with only $1-3 \%$ of all scalp hair. In other parts of the body, unlike on the scalp, more hair is always in the telogen phase (90\% - eyebrows, $70 \%$ - pubic area and the armpits). What is more, the phase usually lasts longer than the anagen phase (except for the armpits) [2].

The proximal section of the hair bulb, composed of actively proliferating cells, is called the hair matrix. This zone is one of the most rapidly growing tissues in the human body and, at the same time, one of the most sensitive to damaging factors [1].

Cytostatic drugs affect hair in a number of ways [3]:

- interruption of the anagen phase of the hair cycle without transition to the telogen phase - so-called anagen hair loss (Lat. anagen effluvium) - caused by cyclophosphamide, etoposide, topotecan and paclitaxel,

- accelerated transition from the anagen phase to the telogen phase - so-called telogen hair loss (Lat. telogen effluvium), caused by methotrexate, 5-FU and retinoids.

The type of hair loss, its severity and period required for hair regeneration, are features specific to different cytostatic drugs or their combinations.

The high proportion of anagen-phase hair on the scalp makes it especially vulnerable to cytostatics. Anagen alopecia results from a range of processes. Cytostatic agents have a strong adverse effect on the intense proliferation of matrix cells, causing hair bulb atrophy and shortening of the hair root sheath. The hair then becomes weaker due to loss of integrity. It also becomes more loosely attached because of cytostatics affecting the internal hair root sheath. Hair which breaks away at the skin surface has a characteristic bayonet shape [3]. Anagen alopecia is usually diffuse and progresses to nearly total hair loss within a short period. The process of hair loss can start within 1-2 weeks after a single dose of a cytostatic agent. As a rule, alopecia is visible during the first chemotherapy cycle, within 3 weeks after commencement of therapy. The process reaches its peak after 2-3 months of treatment. Facial hair, as well as hair in the pubic and armpit areas, falls out much later because these regions have less hair in the anagen growth phase. New hair, sometimes different in colour and structure, starts to grow 1-2 months after the completion of chemotherapy.

Telogen alopecia is the latest type to appear. It starts 3-4 months after initiation of chemotherapy and is scattered in nature. Hair lost to telogen effluvium does not start growing back until 3-6 months after the end of chemotherapy [3].

Telogen alopecia can become more severe in response to a number of non-oncology drugs and concomitant diseases [4]. On the other hand, some cancer types, irrespective of chemotherapy and even before the initiation of treatment, can themselves induce hair loss. These are: acute myeloid leukaemia, T-cell leukaemia, lung cancer, breast cancer and stomach cancer [5].
Progressive hair loss due to chemotherapy may ultimately spread over the whole body. Prolonged alopecia, or event permanent loss of hair, can accompany high doses of combination chemotherapy with cyclophosphamide, thiotepa and carboplatin before bone marrow transplant, and the busulfan + cyclophosphamide regimen [3].

\section{Physical methods reducing blood flow through the scalp}

Existing physical methods of hair loss reduction are based on: mechanical compression of the scalp, cold (hypothermia) and the effect of an electric field. The first two methods seek to reduce the flow of blood through the scalp, while the third one stimulates hair growth.

\section{Scalp compression}

Scalp compression is the oldest of the methods and its importance as an independent technique is only historical. It was the topic of a range of scientific studies published in 1966-1982 [6].

The method utilized a pneumatic tourniquet or a set of round rubber bands compressing the scalp mechanically to decrease local blood flow through the vessels, thereby slowing the transport of the cytostatic agent to the hair follicle area.

The most frequently used compression device was a pneumatic tourniquet equipped with a manometer to enable ongoing monitoring of the degree of scalp compression. An even distribution of pressure on the scalp surface carried a lower risk of ischaemic nerves damage than elastic rubber bands. Exerting pressure of not more than $150 \mathrm{~mm}$ $\mathrm{Hg}$ for a maximum of 1 hour is recognized as physiologically safe, resulting in no ischaemic damage to tissues (nerve cells in particular). The recommendation was to maintain the compression at a level between 40 and $70 \mathrm{~mm} \mathrm{Hg}$ above systolic blood pressure. This approach ensures maximum protection of hair follicles, as well as taking into account the possibility of pressure variation in a scope similar to pressure noted in patients in the perioperative period [7]. The method was typically used in patients without arterial hypertension or severe atheromatosis, with cancer types other than leukaemia and without brain metastases [7].

In order to sufficiently limit local blood perfusion, studies usually involved compression exceeding systolic blood pressure by at least 10-50 mm Hg (Table 2). Compression was typically applied immediately, or 5 minutes, before the administration of cytostatic agents and was continued during therapy until 5, 7 or 30 minutes after its completion [8].

For a method to be effective, the chemotherapeutics considered should have a short serum half-life and should be very quickly eliminated from blood together with their metabolites. A particularly important pharmacokinetic parameter of the cytostatic agent is half-life in the distribution phase, or $T_{1 / 2 \alpha}$ [8]. In this phase the drug achieves shortterm peak concentration in the blood immediately following i.v. administration, which however drops rapidly as the cytostatic penetrates into the tissues (Table 3) [9].

The scalp compression method was used in mono- and combination chemotherapy with cyclophosphamide, vin- 
Table 2. Comparison of the most important scalp tourniquet studies [8]

\begin{tabular}{|c|c|c|c|c|c|c|}
\hline $\begin{array}{l}\text { Reference, } \\
\text { year of } \\
\text { publication }\end{array}$ & $\begin{array}{c}\text { Difference } \\
\text { between scalp } \\
\text { tourniquet } \\
\text { pressure and } \\
\text { systolic pressure } \\
(\mathrm{mm} \mathrm{Hg})\end{array}$ & $\begin{array}{l}\text { Tourniquet } \\
\text { timing } \\
\text { (minutes) } \\
\text { before/after } \\
\text { drug injection }\end{array}$ & $\begin{array}{l}\text { Cytostatic } \\
\text { drugs and } \\
\text { their doses, } \\
\text { number of } \\
\text { cycles }\end{array}$ & $\begin{array}{l}\text { Number } \\
\text { of subjects } \\
\text { (experimental } \\
\text { group/control } \\
\text { group) }\end{array}$ & $\begin{array}{l}\text { Assessment } \\
\text { parameters } \\
\text { for measuring } \\
\text { alopecia }\end{array}$ & Results \\
\hline $\begin{array}{l}\text { Pesce et al. } \\
\text { (1978) [10] }\end{array}$ & $30-50$ & $5 / 20$ & $\begin{array}{c}\text { doxorubicin } \\
30-50 \text { mg, } \\
\text { cyclophosphamide } \\
300-600 \mathrm{mg} \text { over } \\
3 \text { days, } \\
\text { vincristine } 1-2 \mathrm{mg} \\
\text { teniposide } 50 \mathrm{mg} \\
\geq 4 \text { cycles }\end{array}$ & $37 / 31$ & not specified & $\begin{array}{c}\text { no or minimal } \\
\text { hair loss } \\
\text { (number } \\
\text { of subjects in } \\
\text { experimental } \\
\text { group/control group): } \\
\text { 25/9; alopecia: } 12 / 22\end{array}$ \\
\hline $\begin{array}{l}\text { Soukop } \\
\text { et al. }(1978)^{\star} \\
{[11]}\end{array}$ & 10 & $\begin{array}{l}\text { at moment } \\
\text { of starting } \\
\text { injection /30 }\end{array}$ & $\begin{array}{c}\text { doxorubicin } \\
50 \mathrm{mg} / \mathrm{m}^{2} \text {, } \\
\text { cyclophosphamide } \\
500 \mathrm{mg} / \mathrm{m}^{2} \text {, } \\
\text { vincristine } 1 \mathrm{mg} / \mathrm{m}^{2} \\
1-6 \text { cycles }\end{array}$ & $14 / 19$ & $\begin{array}{l}\text { when patient } \\
\text { began } \\
\text { wearing a wig }\end{array}$ & $\begin{array}{c}\text { mean time } \\
\text { to alopecia } \\
\text { (weeks): } 10.3 \\
\text { (experimental } \\
\text { group); } \\
4.2 \text { (control group) }\end{array}$ \\
\hline $\begin{array}{l}\text { Lovejoy } \\
(1979)^{*} \\
{[7]}\end{array}$ & 50 & $\begin{array}{l}\text { at moment } \\
\text { of starting } \\
\text { injection /15 }\end{array}$ & $\begin{array}{c}\text { doxorubicin } \\
60-100 \mathrm{mg} \\
\text { (total dose } \\
\text { 180-315 mg/m²); } \\
\text { 2-4 cycles (single, } \\
\text { every } 3 \text { weeks) }\end{array}$ & $3 / 3$ & $\begin{array}{l}\text { independent } \\
\text { judges according } \\
\text { to graded scale, } \\
\text { subject photos, } \\
\text { evaluation } 3 \text { weeks } \\
\text { after receiving } \\
\text { total dose }\end{array}$ & $\begin{array}{c}\text { Hair loss } \\
\text { (number of } \\
\text { subjects in } \\
\text { experimental } \\
\text { group/control } \\
\text { group): } \\
17 \%( \pm 14 \%) / 69 \% \\
( \pm 32 \%)\end{array}$ \\
\hline $\begin{array}{l}\text { Maxwell } \\
(1980) \\
{[12]}\end{array}$ & 10 & $\begin{array}{l}\text { at moment } \\
\text { of starting } \\
\text { injection } \\
\text { /differences } \\
\text { in completion } \\
\text { times }\end{array}$ & $\begin{array}{l}\text { cyclophosphamide } \\
40 \mathrm{mg} / \mathrm{kg}, \\
\text { methotrexate } \\
0.6 \mathrm{mg} / \mathrm{kg}, \\
\text { vincristine } 2 \mathrm{mg}, \\
\text { actinomycin } 2 \mathrm{mg} ; \\
\geq 4 \text { cycles }\end{array}$ & $5 / 4$ & $\begin{array}{l}\text { independent } \\
\text { judges according } \\
\text { to graded scale, } \\
\text { subject photos }\end{array}$ & $\begin{array}{c}\text { no significant } \\
\text { differences } \\
\text { between } \\
\text { experimental } \\
\text { and control groups }\end{array}$ \\
\hline
\end{tabular}

Control group - patients receive chemotherapy without scalp tourniquet

* randomization

cristine, methotrexate, doxorubicin and teniposide [7, 10-12]. Even though the method was demonstrated to have a moderately protective effect, it needs to be noted that the studies were performed in small groups of patients and, more importantly, some of them lacked random patient assignment or objective criteria for the assessment of severity of hair loss.

When, back in the 1980s, scalp hypothermia emerged as a new method, the two techniques were used in combination (hypothermia and compression caps filled with a special gel). In the course of time, however, the compression method gradually became obsolete as time-consuming and inadequately effective [6].

\section{Scalp hypothermia}

Hypothermia is currently the most frequently used physical method reducing hair loss due to chemotherapy. It is safer for the head tissues and easier in application than scalp compression. The protective effect of the method is attributable to a range of additional mechanisms including: 1. Reduced subcutaneous blood flow caused by contraction of the blood vessel muscle layer due to low temperature (temperatures within the $30-32^{\circ} \mathrm{C}$ range decrease perfusion by up to $25 \%$ of the baseline value) [6].

2. Reduced metabolism of hair follicle cells decreasing their susceptibility to cytostatic damage. An increased lactateto-glucose ratio has been demonstrated in the scalp following hypothermia treatment, with unchanged lactate concentrations in the scalp and abdominal skin not subjected to hypothermia. The mechanism is believed to dominate in the protective hypothermic effect compared to direct reduction of subcutaneous blood flow $[13,14]$.

3. Reduced cellular uptake of cytostatic drugs (depending on temperature). In vitro studies in kidney cells have shown a 4.5 times greater uptake of doxorubicin at $37^{\circ} \mathrm{C}$ than at $4^{\circ} \mathrm{C}$. Furthermore, a correlation has been identified between increased cellular uptake of the drug and increased doxorubicin concentration in the extracellular fluid, which may ultimately increase its local cytotoxicity [15]. So far, however, there have been no in vitro studies to verify whether a similar effect is observed in hair follicle cells.

Hypothermic treatment is currently performed using cooling systems usually comprising a special tight-fitting cap 
Table 3. Initial plasma half-life of cytostatic drugs that cause alopecia [1,9]

\begin{tabular}{|c|c|c|c|c|}
\hline Cytostatic drug & Severity of hair loss & $\mathrm{T}_{1 / 2}$ (i.v.) & $\begin{array}{l}\text { Used in studies } \\
\text { with scalp } \\
\text { tourniquet }\end{array}$ & $\begin{array}{c}\text { Used in studies } \\
\text { with scalp } \\
\text { hypothermia }\end{array}$ \\
\hline cyclophosphamide & \multirow[t]{10}{*}{ severe } & $3-10 h\left(T_{1 / 2 \alpha}\right)$ & \multirow[t]{2}{*}{+} & + \\
\hline daunorubicin & & $40 \min \left(T_{1 / 2 \alpha}\right)$ & & + \\
\hline doxorubicin & & $10 \min \left(T_{1 / 2 \alpha}\right)$ & \multirow[t]{4}{*}{+} & + \\
\hline paclitaxel & & $20 \min \left(T_{1 / 2 \alpha}\right)$ & & + \\
\hline docetaxel & & $4 \min \left(T_{1 / 2 \alpha}\right)$ & & + \\
\hline vinblastine & & $<5 \min \left(T_{1 / 2 \alpha}\right)$ & & \\
\hline vincristine & & $<5 \min \left(T_{1 / 2 \alpha}\right)$ & \multirow[t]{4}{*}{+} & \\
\hline vindesine & & $<5 \min \left(T_{1 / 2 \alpha}\right)$ & & \\
\hline ifosfamide & & $7-15 h\left(T_{1 / 2 \alpha}\right)$ & & + \\
\hline etoposide & & $1.5 \mathrm{~h}\left(\mathrm{~T}_{1 / 2 \alpha}\right)$ & & + \\
\hline methotrexate & \multirow[t]{6}{*}{ moderate } & $30-45 \min \left(T_{1 / 2 \alpha}\right)$ & \multirow{6}{*}{$\begin{array}{l}+ \\
+\end{array}$} & \\
\hline mitomycin & & $2-10 \min \left(T_{1 / 2 \alpha}\right)$ & & \\
\hline actinomycin & & $36 \mathrm{~h}$ & & \\
\hline teniposide & & $5 \mathrm{~h}$ & & \\
\hline topotecan & & $1.6-5.5 \mathrm{~h}$ & & \\
\hline irinotecan & & $5-9.6 h$ & & \\
\hline bleomycin & \multirow[t]{4}{*}{ mild } & $24 \min \left(T_{1 / 2 \alpha}\right)$ & & \\
\hline carmustine & & 15-45 min (dose dependent) & & \\
\hline 5-fluorouracil & & 10-20 min (dose dependent) & & + \\
\hline cisplatin & & $30 \min \left(T_{1 / 2 \alpha}\right)$ & & + \\
\hline
\end{tabular}

filled with cryogel (cold cap). Cooling systems are available in two versions:

- simple - permanently filled with cryogel and replaced with freshly cooled caps every 10-35 minutes, at predefined intervals [16];

- complex - with cryogel circulating through a dedicated tubing system. Cold caps do not need replacement during hypothermic therapy. The cap is connected by tubes with an independent cooling and control system. In addition, the cap is equipped with sensors to monitor scalp temperature [17].

Back in the 1990s there were also hypothermia systems using cold air [18]. Cold caps used in the past had a very simple design based on crushed ice. They failed to adhere to the scalp evenly and had to be replaced frequently during treatment.

The main physical factors affecting the efficacy of hypothermia include hypothermia temperature inside the skin and duration of hypothermic treatment. A physical model which makes it possible to predict the distribution of temperatures and blood flow in the scalp during hypothermic therapy was developed by Janssen et al. in 2005 [19]. The most important predicting physical factors for hypothermia were found to include the temperature to blood flow ratio and thermal resistances of the hair layer and the subcutaneous fat tissue (i.e. thermal insulation). The basic model shows that a reduction in scalp temperature from $34.4^{\circ} \mathrm{C}$ to $18.3^{\circ} \mathrm{C}$ decreases blood perfusion to ca. $25 \%$. Taking into account differences in hair layer thickness (1-4 $\mathrm{mm})$, the temperature inside the skin, at a depth of $1-2 \mathrm{~mm}$, should be lower than $22^{\circ} \mathrm{C}\left(10.1-21.8^{\circ} \mathrm{C}\right)$, with a decrease in blood perfusion ranging from $13 \%$ to $33 \%$. However, no changes in cerebral blood flow and temperature have been observed for contemporary hypothermia applications.

Cytostatic drug administration was commenced after 20-30 minutes of hypothermic treatment, which provides assurance that deeper skin layers are cooled to below $22^{\circ} \mathrm{C}$. The duration of hypothermic therapy after drug administration was determined on the basis of peak blood concentration and elimination half-life of the drug (Table 3), possible interactions between cytostatics and experiences of staff performing hypothermic treatment [20]. The usual duration was 2 hours. A 90-minute cycle was considered sufficient for monotherapy with low doses of doxorubicin $\left(\leq 40 \mathrm{mg} / \mathrm{m}^{2}\right)$ or epirubicin $\left(\leq 50 \mathrm{mg} / \mathrm{m}^{2}\right)$. For doxorubicin and cyclophosphamide used in combination the cycle was prolonged to a total of 3 hours because of the long elimination half-life of cyclophosphamide and interaction between the two agents [21]. Factors increasing the halflife of the drug (liver failure, multiple hepatic metastases) may reduce the efficacy of the method.

Hypothermic treatment may need to be extended if active metabolites of the cytostatic agent are present. For doxorubicin, however, the short elimination half-life ( $T_{1 / 2}=8-25$ min.) only requires short-term hypothermia. On the other hand, the longer elimination half-life of cyclophosphamide $\left(T_{1 / 2 \alpha}=7 \mathrm{~h}\right)$ combined with the presence of a number of active metabolites of the drug, makes it necessary to prolong hypothermic therapy, which lowers its efficacy. If both drugs are used in combination, hypothermia also needs to be longer. 
As for taxoids, long administration (one hour for docetaxel and three hours for paclitaxel) also requires prolonged hypothermia (3 hours).

The extent of hair loss is directly proportional to the concentration of the cytostatic agent used in monotherapy [22]. A similar effect has been observed for polychemotherapy [23].

The efficacy of hypothermic treatment in preventing hair loss due to chemotherapy has been a topic of many studies yielding very divergent results: from positive to negative. In their comparative analysis of 54 clinical trials conducted between 1973 and 2003, Grevelman and Breed confirmed the method's efficacy [24]. Hypothermia was definitely effective in 6 randomized trials and probably effective in 49 non-randomized trials. It proved very difficult, however, to assess the efficacy of hypothermia unambiguously because of a number of factors [24, 25]:

1. Unspecified dose effect (dose-response curve) - referring to the value of effective hypothermia temperature;

2. Different methodologies applied by various trial centres to measure the temperature of the scalp (before and during hypothermic treatment).

3. Differences in the duration of hypothermic treatment before, during and after administration of the cytostatic agent.

4. Differences in hypothermia procedures - cold cap placement on dry hair (with higher thermal insulation) or damp hair.

5. Different design of hypothermia devices (differences in cold cap types and cooling systems).

6. Use of various cytostatics in different chemotherapy regimens.

7. Differences in methodology employed to measure the extent of hair loss and subsequent regrowth.

8. The majority of trials were conducted in small groups of patients, often without randomization. Some of the trials had no control group.

The factors listed above are barriers preventing the development of a uniform standard of hypothermic therapy.

Of all chemotherapy regimens, the efficacy of hypothermic therapy was the highest for anthracyclines or taxoids in monotherapy [14, 26], as shown in the comparative analysis by Grevelman and Breed [24]. The efficacy was lower for higher doses of chemotherapy drugs or combination chemotherapy [16].

Ridderheim et al. compared 13 different multi-drug chemotherapy regimens in 74 female patients receiving hypothermic treatment [17]. A full protective effect of hypothermia on a 10-point scale (VAS =0) was observed for combination regimens: ABVD and FEC, gemcitabine with epirubicin, carboplatin with epirubicin, cisplatin with doxorubicin, topotecan with etoposide, and for monotherapy with taxoids or vinorelbine. A slightly less pronounced protective effect was noted for carboplatin combined with paclitaxel (VAS $=2.5)$, while markedly lower efficacy $(\mathrm{VAS}=6)$ was observed for the TEC combination (paclitaxel, epirubicin, carboplatin). No protective effect was confirmed for the BEP regimen (VAS $=9$ ).

Christodoulou et al. assessed the efficacy of hypothermia in a total of 76 patients receiving multi-drug chemotherapy in 26 different modifications including taxoids, anthra- cyclines, anthracyclines with taxoids, etoposide and ifosfamide [23]. The loss of hair representing $0-25 \%$ of the scalp was regarded as a satisfactory protective effect. The etoposide group was favourably assessed. In the taxoids group a good protective effect was obtained for docetaxel, followed by paclitaxel. In the anthracyclines group a marked difference was identified between the high and low dose of epirubicin, hypothermia being more effective for the latter. No satisfactory effect was noted for the combination therapy of anthracyclines and taxoids or for polychemotherapy containing ifosfamide.

Similar results were reported by Katsimbri et al. [16]. The study confirmed the suitability of hypothermic treatment in multi-drug chemotherapy regimens containing anthracyclines, taxoids or etoposide. However, the protective effect was not adequate for anthracyclines combined with taxoids.

No benefits of hypothermia, however, were demonstrated in a study by Tollenaar et al. [22]. The trial was conducted in 35 patients receiving FAC chemotherapy up to 36 hours after mastectomy according to the EORTC protocol 10854. Hypothermic therapy was not shown to produce an adequate protective effect: only 4 patients did not suffer hair loss. In 12 patients the severity of alopecia was moderate, though they still required a wig, while 19 suffered complete hair loss. In the summary, the authors of the study conclude that hypothermia should not be applied in patients receiving chemotherapy containing cyclophosphamide and doxorubicin, though they do not question the protective effect of hypothermic treatment for doxorubicin in single-drug chemotherapy.

\section{Risks associated with reduction of blood flow through the scalp during chemotherapy}

The most common, and passing, adverse effects of hypothermia are headaches and feeling cold. Hypothermia is thus not used in cold agglutinin disease, cryoglobulinaemia, cryofibrinogenaemia and cold hypersensitivity [24].

The most significant late adverse reaction caused by hypothermia is metastasis to the scalp. The development of metastases is strictly related to the local blood perfusion and cytostatic drug delivery during hypothermic treatment. The scalp is then excluded from the effects of cytostatic treatment and becomes a reservoir for circulating cancer cells [27]. A link with the formation of brain micrometastases seems impossible, as no marked differences in brain temperature were observed during hypothermia [19, 24]. Metastases to the scalp due to hypothermia are relatively rare. Out of 2500 patients undergoing hypothermic therapy in a total of 56 clinical trials, metastases appeared in only 9 patients, of which only two were shown to have a direct link with hypothermia (hypothermia during consolidation therapy for mycosis fungoides and hypothermia during two cycles of daunorubicin, cytarabine and thioguanine in acute myeloid leukaemia [24, 27]). In the other patients metastases to the scalp were observed in the metastatic stage of breast cancer.

\section{Electrotrichogenesis}

Electrotrichogenesis (ETG) is a non-invasive method which utilizes an electric field to stimulate the growth of hair follicles. 
The mechanism underlying ETG is not well explored. The efficacy of ETG is most likely attributable to the influx of calcium ions into the cells via voltage-gated transmembrane ion channels. The process increases ATP synthesis in the mitochondria and activates protein kinases, as well as stimulating protein synthesis and cell division. As a consequence, the anagen phase in hair follicle cells is prolonged. Hair papilla cells are believed to be the most susceptible to the effects of electric stimulation. Ultimately, ETG may stop hair loss and promote hair regrowth [28].

Electrotrichogenesis devices consist of a system of insulated copper plates placed close to the scalp inside a hood or a cap and generating an electric field comprising regular brief pulses on a millisecond scale. Due to appropriate electric field distribution, the highest drop in voltage is at the scalp surface, with minimal exposure in deeper parts of the head. In physical terms the method seems perfectly safe: electric field intensity $(4000 \mathrm{~V} / \mathrm{m})$ represents $2 \%$ of the level determined as safe in experiments conducted on animals exposed to an electric field for more than 10 months, and only $0.001 \%$ of the value recognized as dangerous [28].

The only published clinical study which assessed the effect of an electric field on the scalp in chemotherapy was conducted in patients undergoing CMF therapy [29]. Electrotrichogenesis was applied in a total of 13 female patients, in 12-minute cycles, twice a week for a total of six weeks starting two weeks before the commencement of chemotherapy, then once a week for 12 weeks, followed again by twice a week for two weeks and then once a week for the remaining six weeks after completing chemotherapy. Good results were obtained: out of 13 study patients hair loss was noted in just one person and it was only partial. No adverse effects of ETG or negative sensations of patients undergoing treatment have been reported [28-30].

Despite encouraging results, ETG has not, as yet, been approved by the US Food and Drug Administration. To gain approval, ETG needs to be studied in randomized doubleblind trials.

\section{Summary}

Since hair loss caused by chemotherapy is localized, it offers the possibility to apply controlled treatment based on physical factors. Hypothermic therapy of the scalp has been markedly improved over the past 40 years, with increasingly encouraging results. Unfortunately, different designs of clinical trials investigating hypothermia make them difficult to compare, which results in the absence of a uniform standard of hypothermic treatment. The majority of clinical trials view the technique as effective in some chemotherapy types. The most important aspect seems to be proper selection of the method for the chemotherapy regimen, with the exception of cancers of the haematopoietic and lymphatic systems.

Results obtained in the 2002 trial [29] on the protective effect of an electric field on hair during CMF chemotherapy are very promising. Even though the method's safety has been proven, there have been no further clinical trials investigating the topic.

\section{References}

1. Hesketh PJ, Batchelor D, Golant M, Lyman GH, Rhodes N, Yardley D. Chemotherapy-induced alopecia: psychosocial impact and therapeutic approaches. Support Care Cancer 2004; 12: 543-9.

2. Białynicki-Birula R, Migdał E. Łysienie wywołane przez chemioterapię przeciwnowotworową. Dermatologia Kliniczna 2006; 8: 108-113.

3. Olsen EA. Chemotherapy-induced alopecia: overview and method ology for characterizing hair changes and regrowth. W: The MASCC textbook of cancer supportive care and survivorship. Olver LN (ed.). Springer, New York 2010; 381-6.

4. Kestenbaum TM. Diseases affecting the hair. W: Sauer's Manual of Skin Diseases. Hall JC (ed.). Lippincott Williams and Wilkins, Philadelphia 2006; 307-319.

5. Karakunnel JJ, Berger AM. Hair loss. In: Cancer: principles and practice of oncology. DeVita VT, Lawrence TS, Rosenberg SA (ed.). Lippincott Williams and Wilkins, Philadelphia 2008; 2688-91.

6. Batchelor D. Hair and cancer chemotherapy: consequences and nursing care - a literature study. Eur J Cancer Care. 2001; 10: 147-63.

7. Lovejoy NC. Preventing hair loss during adriamycin therapy. Cancer Nurs 1979; 2: 117-21.

8. Cline BW. Prevention of chemotherapy-induced alopecia: a review of the literature. Cancer Nurs 1984; 7: 221-8.

9. Chabner BA, Longo DL. Cancer chemotherapy and biotherapy: principles and practice. Lippincott Williams and Wilkins, Philadelphia 2006.

10. Pesce A, Cassuto JP, Joyner MV, DuJardin P, Audoly P. Scalp tourniquet in the prevention of chemotherapy-induced alopecia. N Engl J Med 1978; 298: 1204-5.

11. Soukop M, Campbell A, Gray MM, Calman KC. Adriamycin, alopecia, and the scalp tourniquet. Cancer Treat Rep 1978; 62: 489-90.

12. Maxwell MB. Scalp tourniquets for chemotherapy-induced alopecia. Am J Nurs 1980; 80: 900-3.

13. Büllow J, Friberg L, Gaardsting O, Hansen M. Frontal subcutaneous blood flow, and epi- and subcutaneous temperatures during scalp cooling in normal man. Scand J Clin Lab Invest 1985; 45: 505-8.

14. Lundgren-Eriksson L, Edbom G, Olofsson Y, Ridderheim M, Henriksson $\mathrm{R}$. Total prevention of taxoid-induced alopecia by a new model of cold cap. Eur J Cancer 1999; 35, suppl 4: 376.

15. Decorti G, Peloso I, Favarin D, Klugmann F B, Candussio L, Crivellato E, Mallardi F, Baldini L. Handling of doxorubicin by the LLC-PK1 kidney epithelial cell line. J Pharmacol Exp Ther 1998; 286: 525-30.

16. Katsimbri P, Bamias A, Pavlidis N. Prevention of chemotherapy induced alopecia using an effective scalp cooling system. Eur J Cancer 2000; 36: 766-71

17. Ridderheim M, Bjurberg M, Gustavsson A. Scalp hypothermia to prevent chemotherapy-induced alopecia is effective and safe: A pilot study of a new digitized scalp-cooling system used in 74 patients. Support Care Cancer 2003; 11: 371-7.

18. Hillen HF, Breed WP, Botman CJ. Scalp cooling by cold air for the prevention of chemotherapy-induced alopecia. Neth J Med 1990; 37: 231-5.

19. Janssen FE, Van Leeuwen GM, Van Steenhoven AA. Modelling of temperature and perfusion during scalp cooling. Phys Med Biol 2005. 50: 4065-73.

20. Massey CS. A multicentre study to determine the efficacy and patient acceptability of the Paxman Scalp Cooler to prevent hair loss in patients receiving chemotherapy. Eur J Oncol Nurs 2004; 8: 12130

21. Middleton J, Franks D, Buchanan RB, Hall V, Smallwood J, Williams CJ. Failure of scalp hypothermia to prevent hair loss when cyclophosphamide is added to doxorubicin and vincristine. Cancer Treat Rep 1985; 69: 373-5.

22. Tollenaar RA, Liefers GJ, Repelaer van Driel OJ, van de Velde CJ. Scalp cooling has no place in the prevention of alopecia in adjuvant chemotherapy for breast cancer. Eur J Cancer 1994; 30A: 1448-53.

23. Christodoulou C, Klouvas G, Efstathiou E, Zervakis D, Papazachariou E, Plyta M, Skarlos DV. Effectiveness of the MSC cold cap system in the prevention of chemotherapy-induced alopecia. Oncology 2002; 62: 97-102 
24. Grevelman EG, Breed WP. Prevention of chemotherapy-induced hair loss by scalp cooling. Ann Oncol 2005; 16: 352-8.

25. Breed WP. What is wrong with the 30-year-old practice of scalp cooling for the prevention of chemotherapy-induced hair loss? Support Care Cancer 2004; 12: 3-5.

26. Lemenager M, Lecomte S, Bonneterre ME, Bessa E, Dauba J, Bonneterre J. Effectiveness of cold cap in the prevention of docetaxelinduced alopecia. Eur J Cancer 1997; 33: 297-300.

27. Witman G, Cadman E, Chen M. Misuse of scalp hypothermia. Cancer Treat Rep 1981; 65: 507-8.

28. Maddin WS, Bell PW, James JH. The biological effects of a pulsed electrostatic field with specific reference to hair. Electrotrichogenesis. Int J Dermatol 1990; 29: 446-50.

29. Benjamin B, Ziginskas D, Harman J, Meakin T. Pulsed electrostatic fields (ETG) to reduce hair loss in women undergoing chemotherapy for breast carcinoma: a pilot study. Psychooncology 2002 ; 11: 244-8.

30. Maddin WS, Amara I, Sollecito WA. Electrotrichogenesis: further evidence of efficacy and safety on extended use. Int I Dermatol 1992; 31: 878-80.

\section{Address for correspondence}

\section{Tomasz Dąbrowski}

Department of Physics and Biophysics,

Medical University of Gdansk

Dębinki 1

80-211 Gdańsk

e-mail: tomdabro@gumed.edu.pl 